\title{
La "Beya" durmiente: entre reescritura y transposición
}

\section{Favaro, Alice}

Resumen:

Beya. Le viste la cara a Dios

(transposición en historieta de la novela breve Le viste la cara a Dios.

La bella durmiente publicada en 2011) se destaca por abordar un tema muy actual: la trata de mujeres en Argentina. La autora, junto con los dibujos de Iñaki Echeverría, propone una reescritura de La Bella Durmiente y se auto-transpone, siendo la guionista de la historieta. La protagonista es Beya, una joven víctima de las redes de prostitución en el conurbano bonaerense que, después del secuestro, está obligada a prostituirse y vivir en cautiverio. La novela gráfica hace particular hincapié en la reivindicación del cuerpo y la afirmación de sus derechos, la violencia, las conexiones con lo

Cuadernos del Centro de Estudios de Diseño y Comunicación №74

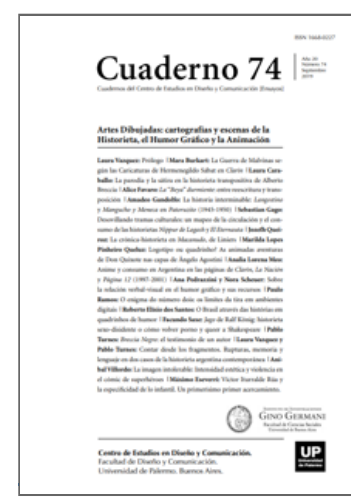

ISSN: 1668-0227

Artes Dibujadas:

cartografías y

escenas de la

Historieta, el Humor

Gráfico y la

Animación

Año XX, Septiembre 2019, Buenos

Aires, Argentina | 256 páginas

descargar PDF

ver índice de la publicación

Ver todos los libros de la publicación

compartir en Facebook

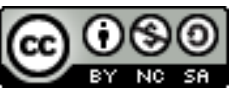

Esta obra está bajo una Licencia Creative Commons Atribución-NoComercialCompartirlgual 4.0 Internacional sagrado y la transmedialidad.

Palabras clave: Trata de personas - comic - transposición.

${ }^{*}$ ) Doctorado de investigación en Lenguas, Culturas y Sociedades Modernas por la Universidad Ca' Foscari de Venecia con la mención de Doctor Europaeus en 2015 con una tesis titulada "Entre la palabra y la imagen. La literatura argentina en historieta. Estudio sobre las transposiciones (estructura, historia y elementos temáticos)". Se ha licenciado en Lenguas y Literaturas Hispanoamericanas en la misma universidad.

La bella durmiente

La bella durmiente del bosque es un cuento de hadas de la tradición oral europea que tiene numerosas versiones. Entre las más conocidas se recuerdan la de Charles Perrault contenida en Los cuentos de Mamá Ganso (1697) y la de los Hermanos Grimm "Rosita de Espino" o "La bella durmiente del bosque" en Cuentos de la Infancia y el Hogar (1812). El Roman de Perceforest, texto literario francés anónimo compuesto hacia 1340, y “Talía, Sol y Luna”, del italiano Giambattista Basile (Pentamerón, 1634) son las versiones más antiguas. La 
historia contada por Basile hace referencia a un estupro mientras que Perrault adapta el cuento a un público de alta burguesía quitándole los aspectos perturbantes; los Hermanos Grimm utilizan una versión similar a aquella contada por Perrault. También Italo Calvino en Cuentos populares italianos (Fiabe italiane raccolte dalla tradizione popolare durante gli ultimi cento anni e trascritte in lingua dai vari dialetti, 1956), propone "La bella durmiente y sus hijos" cuya procedencia se le atribuye a la región de Calabria. El cuento es similar a la versión propuesta por Basile en que la bella durmiente queda embarazada por el amor que el hombre siente por ella y cuyos gemelos se llaman Sol y Luna (precisamente como en el relato del Basile). Aquí también, pues, el autor imputa la causa del embarazo a una violación.

Según la interpretación psicoanalítica del cuento brindada por Bruno Bettelheim el largo período de sueño de la princesa sería el período que precede y sucede la llegada de la primera menstruación en las adolescentes, un tiempo en que las jóvenes mujeres aparecen como pasivas y adormiladas. El despertar corresponde a la necesidad de encarar a sí mismas y al mundo; por más que los padres intenten impedir el florecimiento sexual de sus hijas este se producirá de manera implacable. En el momento en que la niña alcanza la madurez física y emotiva, está lista por el amor. El mensaje implícito sería pues de no apurar el desarrollo normal de los eventos ya que, cuando los tiempos serán maduros, el problema encontrará una solución. En la posmodernidad son muchos los autores que han realizado reescrituras, como por ejemplo la catalana Ana María Matute con El verdadero final de la Bella Durmiente (1995) en que ofrece un final diferente del cuento en que la princesa se encuentra atrapada en una realidad que se demuestra muy diferente de la que parecía, sometida a la voluntad del príncipe y en un estado de pasividad. En Argentina, Luisa Valenzuela ha trabajado el tema de la reescritura de la misma historia pero desde otra perspectiva haciendo hincapié en la reivindicación del cuerpo1 . La escritora ha elaborado la trama de La bella durmiente en algunos cuentos contenidos en Simetrias (1993) en la sección "Cuentos de hades". En el breve relato "4 príncipes 4", compuesto por cuatro breves historias de príncipes, en "Príncipe II" el protagonista es un hombre que besa a todas las mujeres que encuentra despertándolas con su beso, en la espera de su princesa; cuando por fin encuentra a la bella princesa durmiente, la que sabe ser la mujer de su vida, no está capaz de besarla de tan hermosa y tan perfecta que es y se revela ser un incapaz. En cambio en "No se detiene el progreso", que se basa en La bella durmiente sólo en mínima parte, se cuenta de una princesa que se queda dormida y de un príncipe que la despertará después de un siglo pero al final del relato se descubre que es la princesa quien atrapa al príncipe porque de sus brazos crecen unos "zarcillos viscosos que lo atrapan".

Le viste la cara a Dios. La bella durmiente

En cambio la historieta que se analiza en este breve artículo ofrece una versión del cuento desde una perspectiva diferente y distorsionada. Beya (Le viste la cara a Dios) es la primera novela gráfica del catálogo editorial de Eterna Cadencia que se publicó en 2013. Se trata de la transposición de la novela breve Le viste la cara a Dios. La bella durmiente escrito por Gabirela Cabezón Cámara en 2011. La publicación de la novela forma parte de un proyecto de la editorial Sigue leyendo que en 2010 convoca a la escritora, junto con otros escritores latinoamericanos con el objetivo de reescribir un cuento clásico de la literatura para editarlo en formato digital; ella eligió La Bella durmiente proponiendo su reescritura en tres formatos, soportes y editoriales diferentes: ebook, libro y novela gráfica. La autora nació en 1968 en Buenos Aires y se ocupa de la sección cultural del diario Clarín; se introdujo como narradora en el circuito editorial argentino en 2008 con la publicación de La Virgen Cabeza por Eterna Cadencia. 
La novela propone una relectura de un cuento clásico abordando un tema extremamente actual: la trata de mujeres en Argentina. La protagonista es Beya, una joven víctima de las redes de prostitución en el conurbano bonaerense que, después del secuestro, está obligada a prostituirse y vivir en cautiverio en un prostíbulo nauseabundo de Lanús. Existe también una adaptación teatral, realizada por Marisa Busker, que se estrenó en febrero 2016 en los teatros de Buenos Aires.

La literatura y luego la historieta aquí devienen en instrumentos de denuncia social y material documental. El texto fuente tiene un ritmo apremiante con numerosas referencias a la literatura, al arte, a la religión y las creencias populares. El uso de frases muy breves como si la narradora fuera una ametralladora verbal con un realismo desesperado y exasperado en que se describe lo más vulgar y bajo acentúa el lenguaje violento y el ritmo vertiginoso. Las imágenes cruentas en las descripciones de los abusos sufridos por la protagonista comunican al lector el sentido de pérdida de la dignidad y de la posesión sobre el propio cuerpo que paulatinamente percibe la protagonista mientras está violada por sus clientes habituales, entre los cuales se destacan figuras de policías, jueces, curas, políticos. El texto fuente y el hipertexto representan un instrumento de denuncia social y ponen el lector frente a un fenómeno que representa un evidente caso de negación de los derechos humanos.

Beya (Le viste la cara a Dios)

La novela gráfica representa un caso original ya que la autora se autotraspone siendo la guionista de la transposición en historieta. El dibujante, Iñaki Echeverría, nace en Balcarce en 1974, se dedica a la ilustración y a la novela gráfica y publica tiras en Página/12 y en Fierro además de ilustrar libros. La historieta recibió el premio Alfredo Palacios otorgado por el Senado de la Nación por su contributo a la lucha contra la trata de personas. Además fue declarada de interés social y cultural por la Legislatura de la Ciudad de Buenos Aires y recibió el Premio del Lector como mejor libro del año durante la Feria del Libro de Buenos Aires en 2014.

La obra no se puede definir una verdadera transposición en historieta, sería mejor definirla novela gráfica o versión ilustrada de la novela ya que casi no hay globos y prevalecen las imágenes con las acotaciones; se podría situar a mitad entre poema ilustrado y graphic novel en que el texto no está nunca dentro de la viñeta sino al lado. En la historieta, dividida en cinco partes, se hace particular hincapié en la revindicación del cuerpo y la afirmación de sus derechos, la violencia, las conexiones con lo sagrado y la transmedialidad. A través del empleo de muy pocos diálogos, un fuerte contraste entre blancos y negros y la decomposición de las viñetas y de los cuerpos, se enfatizan el dolor, el sufrimiento y la barbaridad del hombre. La novela gráfica narra la historia de la protagonista con imágenes violentas que se mezclan con un registro lingüístico bajo, vulgar, casi pornográfico, cargado de términos típicos del castellano argentino. Los dos lenguajes se cruzan para narrar desde el punto de vista de las víctimas la tragedia de la desaparición de mujeres en manos de las redes de prostitución. La narración, ambientada en las orillas suburbanas, se desenvuelve entre diferentes niveles sociales y culturales de la lengua donde se afirman los derechos del cuerpo de las víctimas en contra de quien lo tortura, viola, reprime, destruye. El cuerpo femenino capturado se convierte aquí en un cuerpo de ficción en que el secuestro con que inicia el relato hace referencia a la última dictadura militar, como se puede leer en una entrevista hecha a la autora:

[...] el relato exige atravesar el guión del secuestro y de esta manera pasa a emparentarse con los relatos de secuestros y torturas de la dictadura y en segundo lugar, lo obliga a emplazarse en las lógicas prostibulares y 
aquí es donde podemos distinguir una larga tradición en la novela argentina y establecer otros vínculos. (Domínguez, 2014, p. 5)

Una primera diferencia con el hipotexto se encuentra en el título en que Le viste la cara a Dios, La bella durmiente se transforma en Beya (Le viste la cara a Dios) donde Beya deviene en nombre de la protagonista en la trasposición y se juega en el mismo sonido "II" - "y" pero el empleo de la "y" en lugar de la "II" transfigura la palabra. El adjetivo deviene en sustantivo, transformado y transfigurado. La protagonista ya no es la Bella durmiente sino que es simplemente Beya, como si también su belleza hubiese sufrido una metamorfosis. Ya en el título pues la transposición ofrece una versión del hipotexto torcido, modificado, asumido desde una perspectiva diferente. La oralidad se impone en la norma lingüística y genera la nueva identidad de la protagonista. El haber añadido como epígrafe: "Aparición con vida de todas las mujeres y nenas desaparecidas en redes de prostitución. Juicio y castigo a los culpables" sitúa al texto en una doble referencia: por una parte la historia de Marita Verón, desaparecida en 2002 en la provincia de Tucumán2 , y los frecuentes casos en Argentina de trata de mujeres; por el otro la referencia a la última dictadura militar. De hecho se intersecan el campo de concentración con el prostíbulo. En la transposición se enfatiza le reivindicación del cuerpo femenino que ya en la primera imagen está representado como si fuera un objeto en venta con detrás un código de barras, como se puede ver en la Imagen 1. La represión de los derechos del individuo en la esclavitud sexual se manifiesta también, a través del lenguaje, en la expresión "cosecha de mujeres" que hace referencia al campo semántico de la agricultura. Los personajes en la historieta no tienen una voz propia, aparecen como si fueran mudos, silenciosos o costringidos al silencio. Hablan a través de las acciones que cumplen pero es el texto que explica lo que acontece, el estado de ánimo, los pensamientos de la protagonista y no los diálogos. De hecho toda la primera parte está caracterizada por el silencio de las imágenes que imprimen un tono de suspenso.

La narración de la metamorfosis que sufre la protagonista acontece y se desarrolla en dos binarios paralelos: por una parte la joven se convierte en una prostituta y aprende el oficio y por el otro entiende que le conviene aparecer como sumisa y obediente y mientras tanto va preparando su venganza: se mantiene fuerte y piensa en cómo reaccionar. Empieza así a delinearse en el texto, después de un denso momento inicial en que el lector sigue el sufrimiento y la humillación de la protagonista en su vida diaria en cautiverio, la necesidad por parte de la víctima de redimirse desde el lado más oscuro de la marginalidad, de la violencia, de la locura, convirtiéndose en una heroína.

Las imágenes violentas que se ven (Ver Imagen 2 y 3) se mezclan con un registro lingüístico bajo y vulgar, un vocabulario prostibulario se podría decir. El lenguaje visual y aquello verbal se compenetran para narrar la tragedia de la desaparición de las mujeres desde el punto de vista de las víctimas. También en la historieta se mantiene el "vos" con que la narradora se dirige al lector para aumentar la cercanía a la narración.

A lo largo de la narración hay numerosos ejemplos, enfatizados en la historieta, de conexiones entre lo sagrado, la muerte y el sexo. La protagonista está paragonada a una Virgen, como en la imagen que sigue en que aparece, como en un díptico, al lado de la Virgen donde la guirnalda de flores que adorna la primera imagen se convierte en una guirnalda de falos en la segunda. (Ver Imagen 4 y 5 )

La religiosidad, exasperada y casi blasfema, es muy presente en la narración y no hay que olvidar que uno de sus clientes es un cura. Las escenas religiosas que aparecen refiguradas son a menudo citas o referencias a pinturas famosas. La protagonista encuentra en la fe un refugio, reza para que su alma sea absuelta de los 
pecados. Hay un paralelismo entre el sufrimiento de la protagonista y el sufrimiento de Cristo, donde se explica que aunque él no pueda saber lo que siente una mujer violada y torturada ha conocido él también el padecimiento, como Beya que aparece aquí crucificada y ornada con capullos de flores que parecen úteros (en la imagen a la derecha). (Ver Imagen 6 y 7 )

El hecho de encontrar amparo en la religión produce en la protagonista un efecto de bilocación y desdoblamiento en que el alma se separa del cuerpo representando una manera para huir de la realidad demasiado atroz: "querés fuga y bilocación, / un espíritu que sepa/ estar en otro lugar,/ muy lejos mas sin morirte,/ vos querés desdoblamiento/ cual místico en viaje astral/ y cantar como San Juan/ la noche oscura del alma" (31). La historia avanza en una continua intersección entre culto y popular sagrado y profano y narra la degradación de Beya con un lenguaje al mismo tiempo descarnado y cargado de violencia. La perspectiva del narrador que focaliza desde la subjetividad de la protagonista se mezcla con la segunda persona que se acerca a la oralidad y que invoca la mujer a actuar, registra las distintas etapas de la trata, la exhorta a cultivar el odio. El uso de la segunda persona enfatiza el desdoblamiento de Beya frente al dolor. Son numerosas las experiencias de viaje fuera del cuerpo de la protagonista, justamente como los testimonios contados por las víctimas secuestradas durante la dictadura militar mientras estaban brutalmente torturadas. En este estado de enajenación física se narran, sin omitir los detalles violentos, el tormento, el delirio místico, la gestación imaginaria del odio, la sed de venganza, la recuperación, donde se lee: "[...] lo que podés es cuidar/ a tu odio como si fuera/ un bebé recién nacido/ [...] el monstruito está hecho/ de todo lo que te duele/ y cuando llegue a su término/ la asquerosa gestación,/ te van a nacer diez púas/ en las puntas de los dedos" $(51,68)$, como se puede ver en la imagen siguiente donde la mujer lleva en el vientre una especie de monstruo donde vuelve el tema del decorado con una flor que parece un útero y un enredo de espinas. (Ver Imagen 8)

La relación con la violencia se manifiesta aquí también, como dicotomía entre civilización -la ciudad-y barbarie -el burdel de Lanús. De hecho es inmediata la referencia a El matadero de Echeverría, al que se alude directamente en la primera estrofa a través de la comparación del cuerpo de la joven con el cuerpo de la vaca y cuyos versos se citan al principio de la historieta: "Si a Matasiete el matambre,/ a vos el resfalar en tu sangre" (24), estrofa que detiene en los roles de torturador y víctima. De hecho la escritora misma en una entrevista afirmó que existe un imaginario nacional de escritura de la violencia al que no puede renunciar y que ya casi no puede pensar la violencia sin referirla a algunos textos literarios. (Domínguez, 2014a, p. 2)

Beya está representada siempre desnuda; en particular se destacan los dibujos que siguen, en que aparece, antes, con los efectos que tienen en su cuerpo las continuas administraciones de droga y después, utilizando el estilo del fileteado muy típico del ambiente tanguero porteño, el paralelo entre la mujer y la bestia, como si estuviera esperando ser descuartizada antes de llegar a la carnicería, en que se lee: “[...] como no se acaba nunca/ la cosecha de mujeres/ y eso te lo hacen saber,/ no te vayas a olvidar,/ que ellos te pueden pasar/ a degüello como a un chancho/ y filetearte después/ como si fueras jamón" (37). (Ver Imagen 9 y 10)

El paralelismo entre mujer y vaca está enfatizado en diferentes partes del texto, por ejemplo en la frase: "[...] Como a una marioneta./ No te matan porque sos/ su hacienda y les rendís viva,/ les rinde tu kilo en pie/ o más bien en cuatro patas/ ya lo dice el cuervo rata:/ 'Mis putas me rinden más/ que las vaquitas al Farmer/ más poronga de mis clientes'" (36) donde la mujer se convierte en mera carne para ser fuente de placer y de ganancia. 
El estilo utilizado por el dibujante, a través de una estética en blanco y negro que recuerda los fanzines de los años 80 , en la representación de los dibujos, es violento precisamente como el lenguaje y emplea una linea gráfica marcada en que predominan los negros y las sombras. El texto aparece sólo después de las quince páginas del capítulo inicial y se presenta adyacente a los dibujos que lo ilustran, como si fuera subordinado a la imagen. Se utilizan fragmentos del hipotexto pero a veces con leves modificaciones u omisiones en algunas partes. El negro predomina en el blanco y las imágenes tienen un fuerte corte expresionista alemán como si se tratara de xilografías y de incisiones más que de dibujos. Hay un contraste intenso entre blanco y negro en una estética basada en un cambio continuo de planos. La descomposición de las viñetas rectangulares procede, a medida que avanza el secuestro, paralela a la descomposición y deshumanización que está sufriendo a nivel psicológico y físico la protagonista. El zoom en los detalles en que se multiplican los puntos de vista y el alejamiento con vistas que proceden del alto en diferentes momentos de la narración enfatiza el efecto de desdoblamiento que siente la joven. En la composición de la página la lógica habitual de las viñetas está invertida ya que están desparramadas en la hoja. Las partes blancas subrayan un diferente ritmo de la narración y representan el martirio de la esclavitud sexual que induce a la "Beya durmiente" a fingirse inconsciente, a perderse o desdoblarse mentalmente para resistir a la violencia, al "ablande" al cual está sometida. Para construir el universo gráfico de Beya Echeverría se nutre de una mezcla de estilos de los grandes dibujantes argentinos relatando no sólo una sucesión de acontecimientos sino también de atmósferas y de climas. Dibuja viñetas oscuras, manos, bocas, órganos genitales en una historieta que aparece casi pornográfica. Estas secuencias fragmentarias están intercaladas con imágenes a página entera en las que están presentes alusiones a la iconografía cristiana donde se refugia la protagonista. (Ver Imagen 11 y 12)

El texto construye un cuento hipnótico a partir de una modulación rítmica repetitiva y que en algunos puntos tiene la fuerza de un texto religioso. El choque entre el lenguaje culto y el lenguaje bajo, típico del habla porteña y rioplatense se mezcla con las escenas de las torturas y violaciones alternadas a las referencias a las pinturas notorias. Narrado casi con el ritmo del rap con versos cortos, octosílabo, un léxico fuerte y palabras que evocan imágenes continuamente, la escritora adopta una estrategia narrativa extremadamente visual, en ciertos momentos musical, que se cruza de manera natural con el estilo de Iñaki Echeverría cuyas imágenes en blanco y negro fuertemente contrastantes dan lugar a un cuento muy duro tanto desde el punto de vista del contenido como desde lo estético. El lenguaje también, de hecho, es violento y casi pornográfico y permite, metiéndose en la psiquis del personaje principal, acceder a diferentes planos de lectura. El ritmo del cuento está escandido por el subseguirse alternativamente de blancos y negros en que las palabras disparan imágenes y la voz en off de la narradora propone la venganza: "se entrelazan dos partes de la novela, la que narra el exceso de la opresión, esclavización, pornografía y muerte con la del deseo de vida y la potencia femenina". (Domínguez, 2013, p. 143)

La yuxtaposición de dimensiones diferentes en que el texto se ubica en distintos momentos de la historia cultural donde hay una continua mezcla de popular, erudito y la experiencia religiosa, que aparece como posibilidad de salvación, se manifiesta a través de la transmedialidad e intertextualidad. De hecho las referencias a pinturas notorias es muy evidente, por ejemplo en las imágenes 11 y 12; en que en la primera hay una referencia a Adoración de los pastores (1612-1614) de El Greco, en la segunda a La trasfiguración (1518-1520) de Raffaello. En la pintura de Raffaello se puede notar en la parte abajo a la izquierda una referencia a un particular de El Juicio Final (1535-1541) de Michelangelo (Ver Imagen 13 y 14) y aquí La última cena (1495-1498) de Leonardo (Ver Imagen 15). 
Las pinturas están mezcladas entre períodos históricos y estilos artísticos diferentes: se entrecruzan arte moderno y contemporáneo, como por ejemplo la referencia a El beso (1907-1908) de Klimt y a Maternidad. Las tres edades de la mujer (1905) o Eperanza II. Visión, fecundidad, leyenda (1907-1908) del mismo pintor representado en la imagen de Beya que vimos más arriba en que está dibujada como una mujer embarazada y cuyo estilo retoma el adorno típico de Klimt (Ver Imagen 16).

Además de las alusiones literarias y artísticas hay también referencias al cine en que la protagonista está paragonada a la protagonista de Kill Bill que busca venganza.

La representación del mundo de las orillas suburbanas desde lo más oscuro de la marginalidad relata una entre las tantas trágicas historias de mujeres quebradas víctimas de la violencia masculina en que, una vez más, quien gana es el más fuerte. Cuerpo y voz se separan, la narración se proyecta desde un vos, utilizando una segunda persona, en que en algunos puntos parece sea Beya que habla directamente al lector y en otros la autora que se dirige a la protagonista. Beya se aparta de la primera persona y se convierte en una tercera. Esta voz violenta, imperativa, desencarnada construye otra salida para la narración. La mezcla de registros entre oral/bajo y culto/con referencias literarias y culturales da lugar a una suerte de fábula de redención en que se vuelca el mito femenino infantilizado congelado en la belleza y donde el final inesperado en que la mujer deviene en justiciera es muy diferente de lo que en realidad acontece a las víctimas: la desaparición o la muerte. La mujer pasa aquí de una condición de víctima a una de vengadora.

El personaje llega a un punto extremo en términos de experiencias límite sobre el cuerpo donde el sometimiento, el cuerpo mercancía deviene espacio de resistencia. El cuerpo

Es decididamente un territorio de imaginación biopolítica [...] exiliado de su vida por el delito de la trata de personas, enajenado por la explotación sexual y el terror desatado en el puti-club, llevado a la extenuación de sus funciones vitales y subjetivas. (Domínguez, 2014b, p. 23)

El cuerpo de la mujer es aquí un disparador narrativo en que la literatura sirve como instrumento de denuncia política y social en el que el tema de la trata de personas se conecta a un problema actual. De hecho en una continua mezcla entre moderno y postmoderno entre artes y estilos, el texto, aunque tenga referencias a diferentes períodos históricos que se refieren a la historia nacional y a la violencia política, es cuanto más actual por su estilo, lenguaje y por el tema que trata. El cuerpo es un cuerpo desnudo, abandonado en la soledad del cautiverio, acurrucado, en que la mujer se cubre el rostro con los brazos, se encierra en sí misma, desaparece. Un cuerpo amatambrado (Dominguez, 2014b, p. 25) que asume el papel principal en que lo más abyecto estalla, llevado a la aniquilación, al extremo, donde se retrata la corporalidad en su parte más animal y baja.

En la historieta, a través del modo en que se narran los cuerpos atravesados por la violencia, "el formato del cómic soporta los silencios de un cuerpo robado y ultrajado que interpela al lector exigiendo juicio y castigo a los responsables de la trata de personas" (Rios, p. 1). De hecho la transposición en historieta exacerba lo trágico de la historia contada donde el cuerpo ultrajado y dominado físicamente y moralmente por el otro-hombre es un cuerpo que está secuestrado y prostituido justo por ser un cuerpo femenino3 . En el espacio del prostíbulo, un espacio imaginario poblados por vidas aniquiladas en tránsito y en trampa, la potencia del lenguaje y del estilo narrativo de Cabezón Cámara se fusiona con las imágenes cautivadoras, sin censura, de Echeverría. El resultado es una novela gráfica con un estilo muy actual y agresivo que atrae el lector desde el principio hasta el 
final en una única lectura, casi sin respirar, donde resuenan palabras violentas y vulgares. Todo bajo una atmósfera de terror y horror que nos acerca, aún más, al sufrimiento de la víctima y al deseo de hacer justicia y donde hipotexto e hipertexto dialogan continuamente.

Notas

1. Véase Regazzoni, Susanna (2010), “Cuando la curiosidad te salva”. El Barbazul de Luisa Valenzuela”.

2. María de los Ángeles Verón tenía 23 años al momento de ser secuestrada el 3 de abril de 2002. El 8 de febrero de 2012 comenzó en Tucumán el proceso con 13 imputados; luego de varias postergaciones, el 10 de diciembre de 2012 el Tribunal dictó la absolución de los 13 imputados. Los abogados de la familia Verón presentaron inmediatamente la apelación en la Cámara de Casación, al tiempo que hicieron un pedido de Juicio Político a los magristados, por mal desempeño al maltratar y discriminar a las víctimas durante su declaración testimonial en el proceso. La apelación en la Corte Suprema Tucumana fue a favor de la familia Verón, señalando como culpables a 10 de los imputados. Todos los condenados debían esperar la sentencia firme cumpliendo prisión preventiva. Pero fueron liberados, en su totalidad, hasta que la sentencia quedara firme. El viernes 4 de noviembre de 2016 la Corte Suprema de Tucumán publicó su rechazo a la apelación de los delincuentes, por lo que los abogados de la familia Verón pidieron inmediatamente la prisión de todos los condenados. Para ampliar véase: http://casoveron.org.ar/

3. Nora Domínguez define esta novela como perteneciente al género del "barroso femenista". (Domínguez, 2013, p. 145)

Bibliografía

Bettelheim, B. (1994). Psicoanálisis de los cuentos de hadas. Barcelona: Crítica.

Cabezón Cámara, G. (2011). Le viste la cara a Dios. La bella durmiente. Barcelona: Sigueleyendo.

Cabezón Cámara, G. y Echeverría, I. (2013). Beya. Le viste la cara a Dios. Buenos Aires: Eterna Cadencia.

Calvino, I. (1956). "La bella addormentata e i suoi figli", Fiabe italiane raccolte dalla tradizione popolare durante gli ultimi cento anni e trascritte in lingua dai vari dialetti da Italo Calvino. Turín: Einaudi.

Domínguez, N. (2013). "Movimientos ficcionales y no ficcionales de la violencia. Crímenes de mujeres", Aletria. Revista de Estudios de Literatura, $\mathrm{N}^{\circ} 1$, enero-abril, Belo Horizonte. . (2014a). "Conversaciones y reenvíos con Gabriela Cabezón Cámara”, Cuadernos LIRICO. Revista de la red interuniversitaria de estudios sobre las literaturas rioplatenses contemporáneas en Francia, $N^{\circ} 10, p p$. $1-6$.

(2014b). “La trilogía de Gabriela Cabezón Cámara: entre el enclave formal y la sedición de los cuerpos", Palchevich, M. y Rivara, A. L. (eds.), Literatura y política. Boletín de la BCN, № 128, Buenos Aires: Biblioteca del Congreso de la Nación, pp. 23-29. 
Matute, A. M. (1995). El verdadero final de la Bella Durmiente. Barcelona: Destino.

Regazzoni, S. (2010). "Cuando la curiosidad te salva. El Barbazul de Luisa Valenzuela”, Serafin, S.; Perassi, E.; Regazzoni, S. y Campuzano, L. (eds.), Más allá del umbral. Autoras hispanoamericanas y el oficio de la escritura. Sevilla: Renacimiento, pp. 213-234.

Rios, M. C. (2016). "Vidas soportadas: de la zoé (bios) a la vida ovillada”, IV Coloquio Internacional "Literatura y vida", 8-10 junio, Rosario.

Valenzuela, . (1996) [1993]. Simetrías. Barcelona: Plaza \& Janes. "El caso Marita Verón”, http://casoveron.org.ar/

Abstract: Beya. Le viste la cara a Dios (transposition in comic of the short novel Le viste la cara a Dios. La bella durmiente, published in 2011), stands out for addressing a very current issue: trafficking of women in Argentina. The author, along with the drawings by Iñaki Echeverría, proposes a rewrite of La bella durmiente and and she becomes the scriptwriter of the cartoon. The protagonist is Beya, a young victim of a prostitution network in the suburbs of Buenos Aires. After the kidnapping, she is forced to prostitute herself and live in captivity. The graphic novel places particular emphasis on the vindication of the body and the affirmation of its rights, violence, connections with the sacred and transmediality.

Key words: Trafficking in Persons - comic - transposition.

Resumo: Beya. Le viste la cara a Dios (transposição em desenhos animados do romance curto Le viste la cara a Dios. La bella durmiente publicada em 2011) destaca-se por abordar um problema muito atual: o tráfico de mulheres na Argentina. A autora, juntamente com os desenhos de Iñaki Echeverría, propõe uma reescrita da La bella durmiente e tornando- -se o roteirista do comic. O protagonista é Beya, uma jovem vítima das redes de prostituição nos subúrbios de Buenos Aires que, após o seqüestro, é forçada a se prostituir e viver em cativeiro. A novela gráfica coloca especial ênfase na reivindicação do corpo e na afirmação de seus direitos, violência, conexões com o sagrado e transmedialidade.

Palavras chave: Trata de pessoas - comic - transposição.

[Las traducciones de los abstracts al inglés y portugués fueron supervisadas por el autor de cada artículo]

La "Beya" durmiente: entre reescritura y transposición fue publicado de la página 43 a página56 en Cuadernos del Centro de Estudios de Diseño y Comunicación №74 